\title{
THE SIMULATION RESEARCH OF RECIPROCATING DIVIDING SHEAR KNIFE BASED ON ADAMS
}

\author{
Wang Dandan ${ }^{1}$, Huang Lixin ${ }^{2}$, Yu Tao ${ }^{3}$ \\ ${ }^{1}$ Shanghai University of Engineering Science, Advanced manufacturing research center, Shanghai, 201600, China \\ ${ }^{2}$ Shanghai University of Engineering Science, Advanced manufacturing research center, Shanghai, 201600, China \\ ${ }^{3}$ Shanghai University of Engineering Science, Advanced manufacturing research center, Shanghai, 201600, China
}

\begin{abstract}
The reciprocation shear knife used in segmentation of water hyacinth root separation, should minimize the cutting resistance and power consumption in order to improve the work efficiency, because the work efficiency is the main factor. So as to find a better way of cutting, Models of each cutting way are built, and F - $t$ and $v$ - $t$ curve are studied by using ADAMS for each kind of cutting way. And then the better way of cutting will be used for the simulation and optimization.
\end{abstract}

Keywords: Split shear knives, cutting direction, ADAMS

\section{INTRODUCTION}

This paper is to study the reciprocating blade for dividing shear cutting water hyacinth, the choices are standard $\Pi$ type cutter. Cutting width is $1.5 \sim 2.0 \mathrm{~m}$, belonging to support cutting reciprocating cutter work, fixed blade fixed and moving blade to cut a certain speed. Dividing the velocity shear knife cutting quality directly affects the size and the direction of the shearing knife cut dividing stem cutting resistance and its power consumption is closely related to, and dividing the shearing blade cutting speed and cutting effect on productivity is also affected. Therefore, the research division at a reasonable cut knife cutting angle cutting is necessary.

\section{SPLIT SHEAR DEVICE}

As shown in Fig.1, the shearing device is divided by a hydraulic motor, driving the crankshaft connecting rod mechanism, scissors mechanism, mounting plates, installed on the bow deck first.

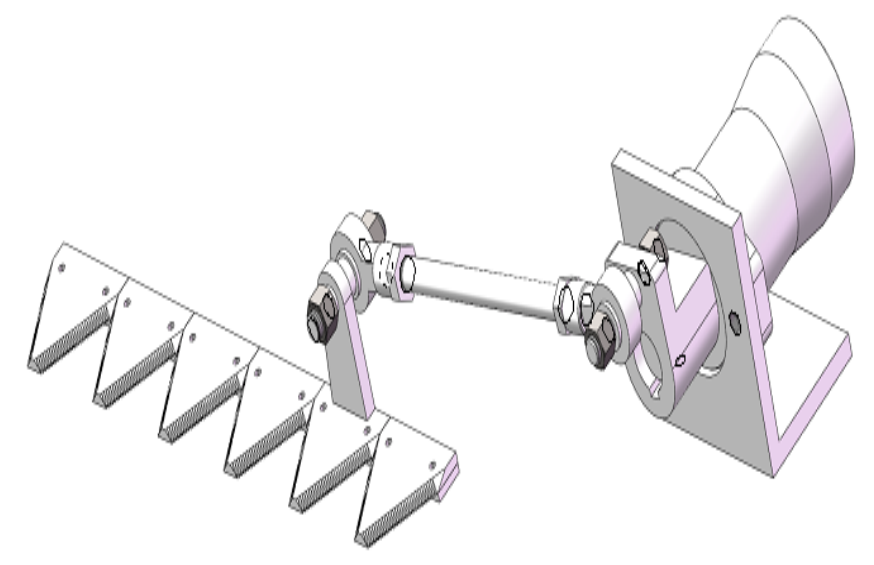

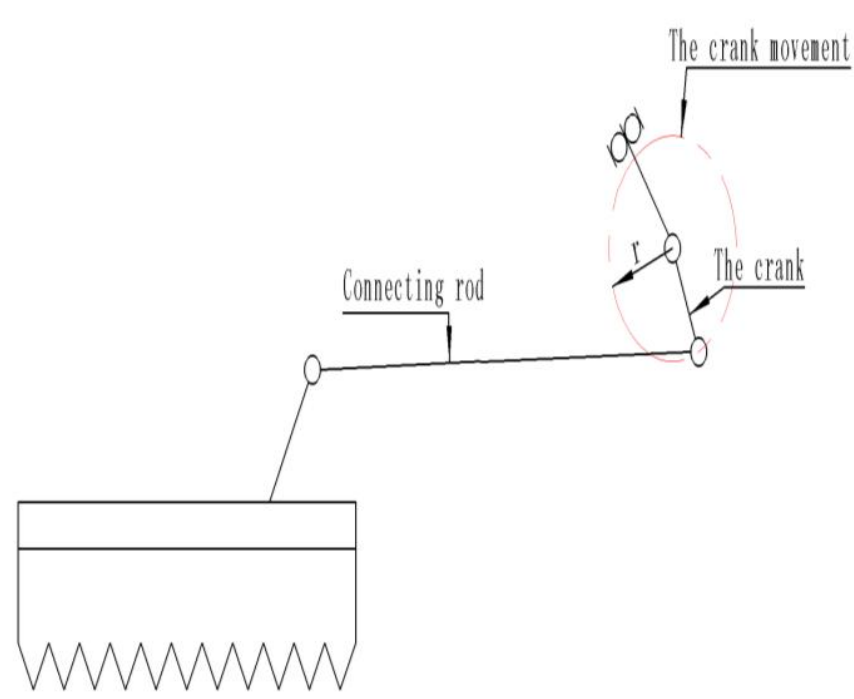

Fig -1: The diagram of divided shearing mechanism

In order to make the split shear mechanism of simple structure, easy maintenance and replacement, a standard $\Pi$ type cutter. Standard П-type cutter by moving blade, blade guard, a pressure blade, a friction plate and other components [2]. The movable blade is driven by crank linkage, reciprocate, so that the moving blades and fixed blades form a stable shear deputy. Its structure diagram shown in Fig. 1

\section{SIMULATION OF CUTTING DIRECTION}

The quality of the cutting means cutting not only the design of its structure and parameters related to the physical properties of crop stalks are also closely related, such as fiber orientation stalk. Crop stalks constituted by cellulose, the fiber direction parallel to the stem axis, so the direction of the cutter to cut the stem with its cutting resistance and power consumption are closely related. 
Three cutting direction as shown in Fig.2 [7] :(1) Crosssection: the cut surface and the cutting direction perpendicular to the axis of the stem (Fig.2a); (2) The miter: the cutting surface and the stem axis deviation, but cutting direction perpendicular to the axis of the stem (Fig.2b); (3)Cutting back: cutting surface and cut the stem axis directions and skewed (Fig.2c).

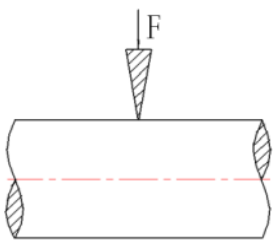

a

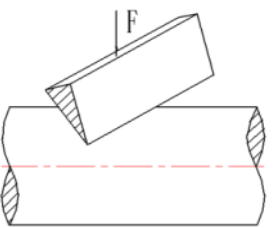

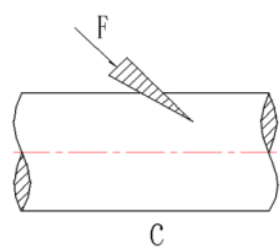

C
The following use ADAMS to verify the actual cutting process, cutting back is a relatively good way of cutting. First established in ADAMS simulation model, as shown in Fig. 3

Fig -2: Three kinds of cutting direction

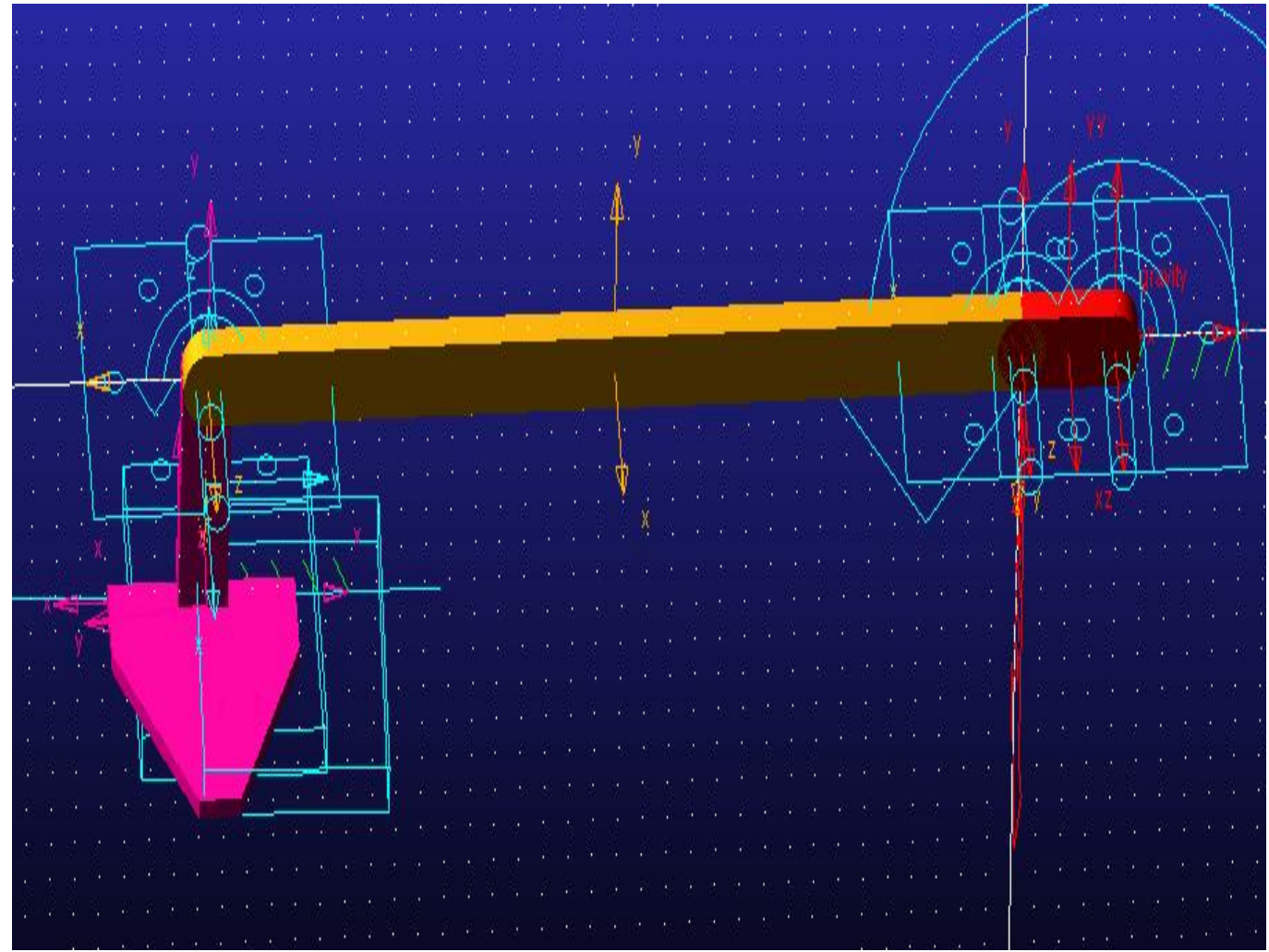

(a) 


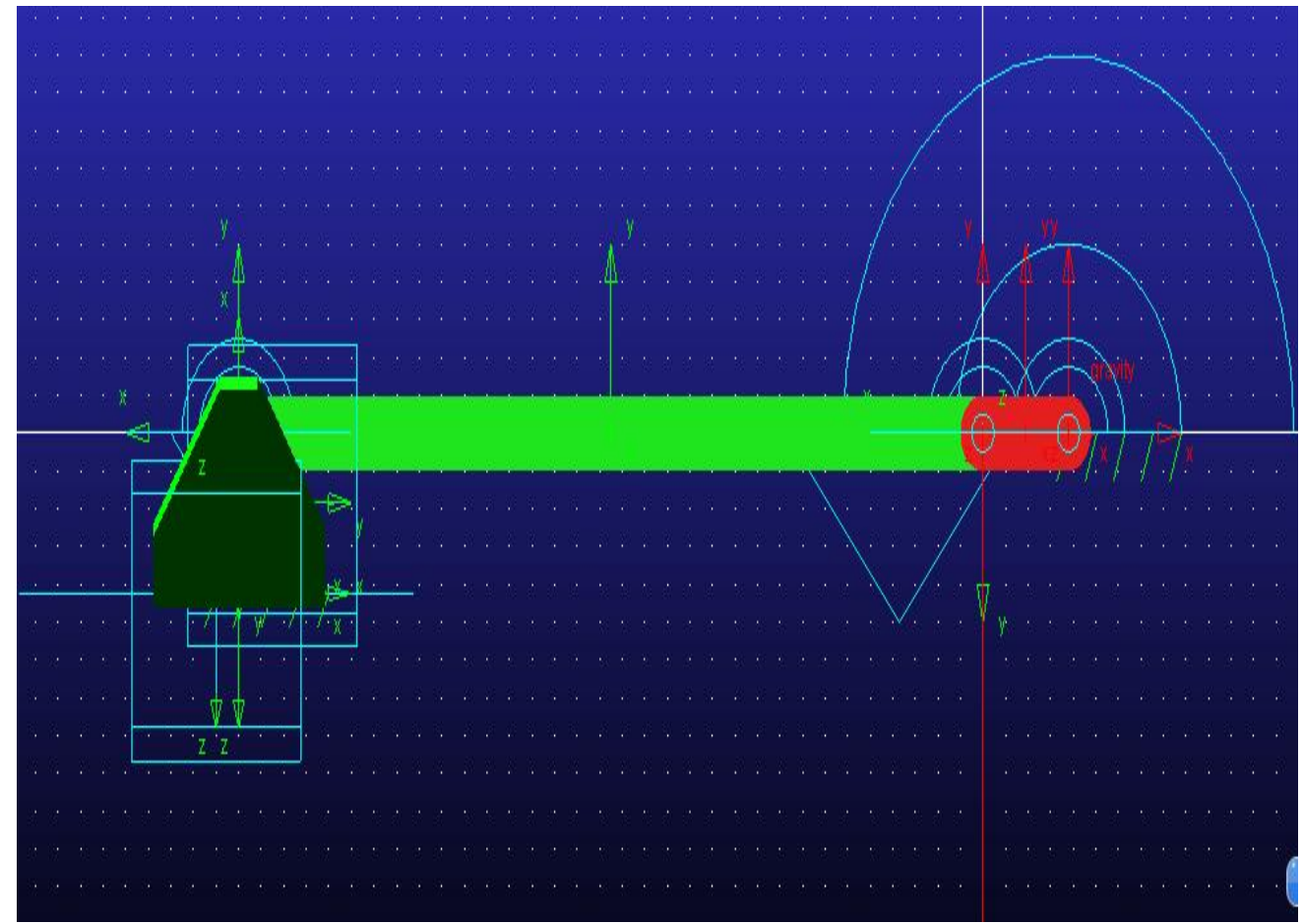

(b)

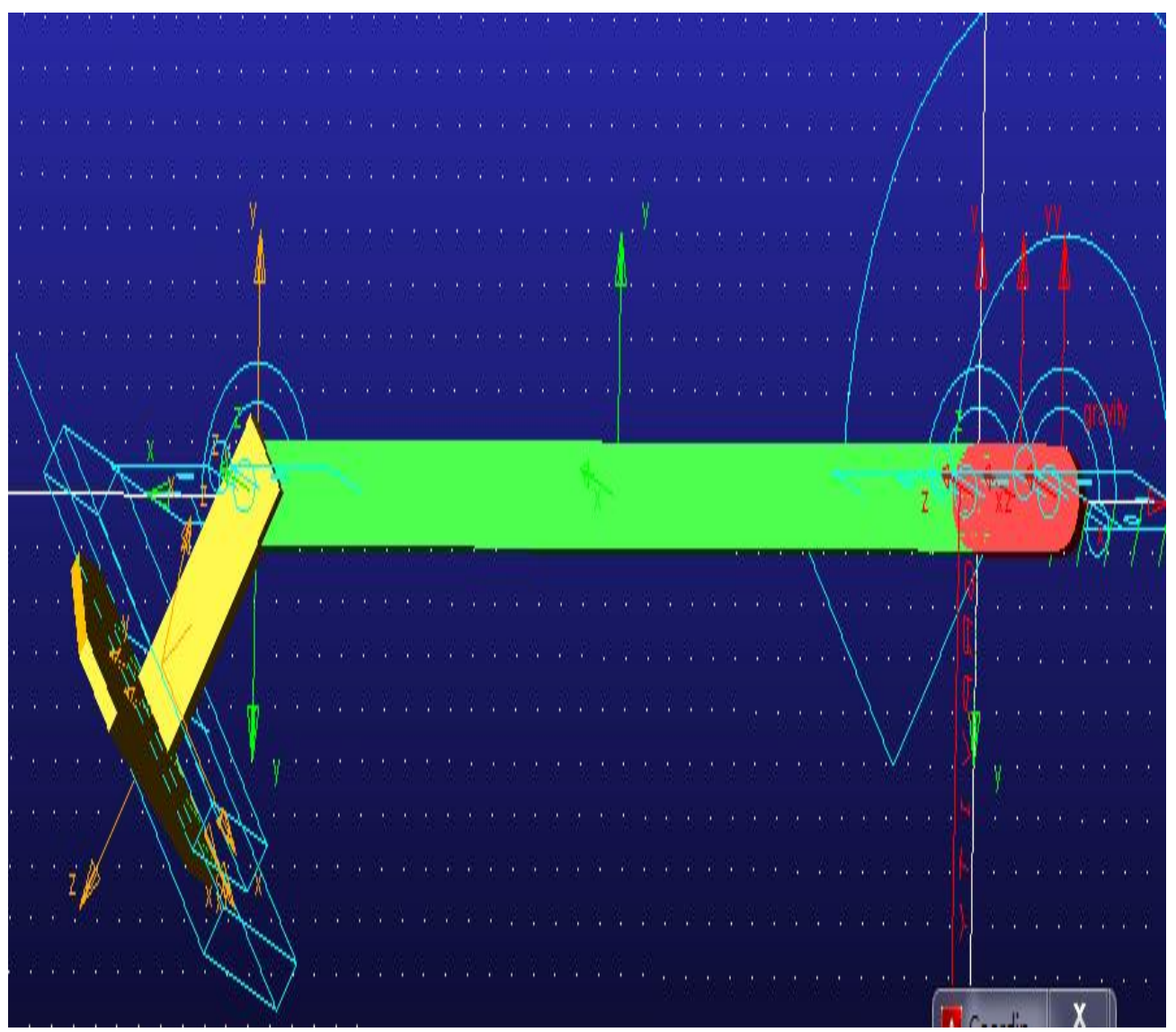

(c)

Fig -3: Three kinds of the simulation model of cutting way

And cutting of the miter angles are set at $45^{\circ}$, the simulation analysis can be obtained for each of the cutting mode $\mathrm{v}-\mathrm{t}$ graph, Ft graph and a torque curve. Cutting mode of the three F-t graph performed Comparison, as shown in Fig.4. 


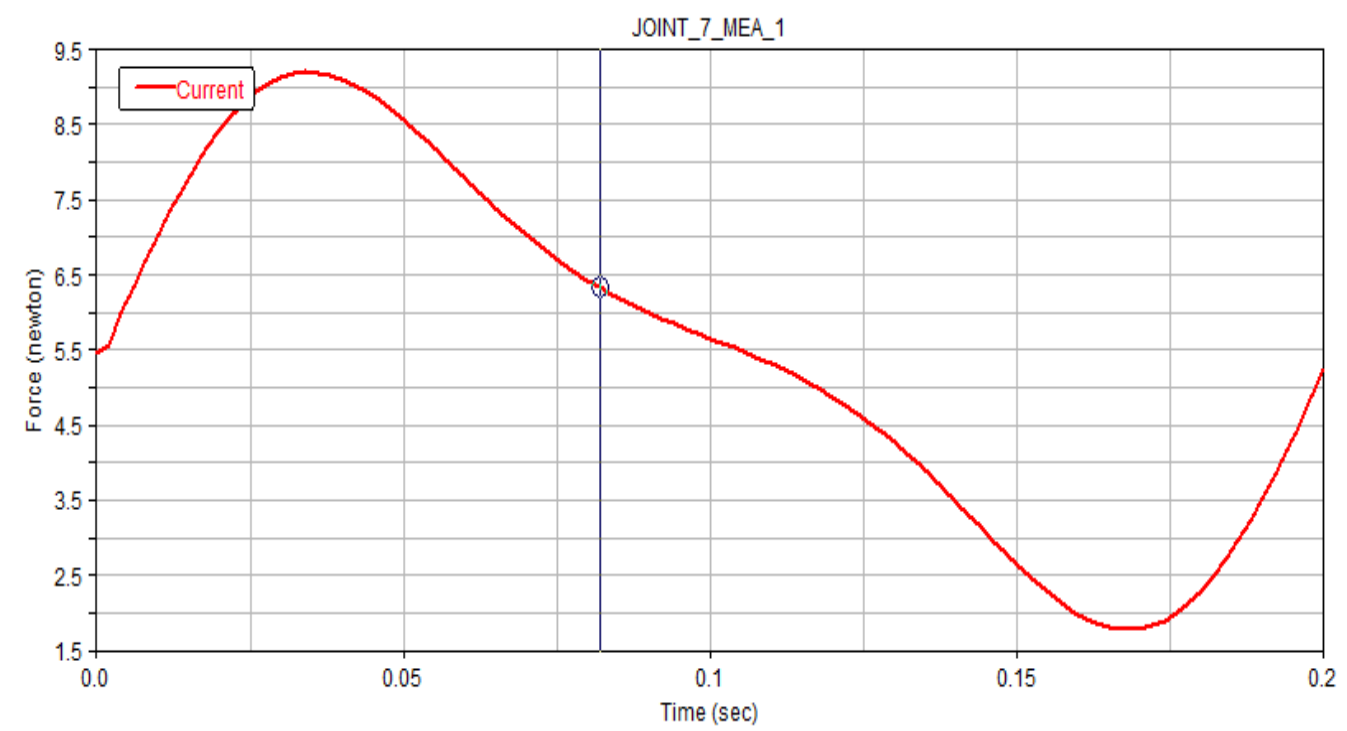

(a)The crosscutting ADAMS simulation result

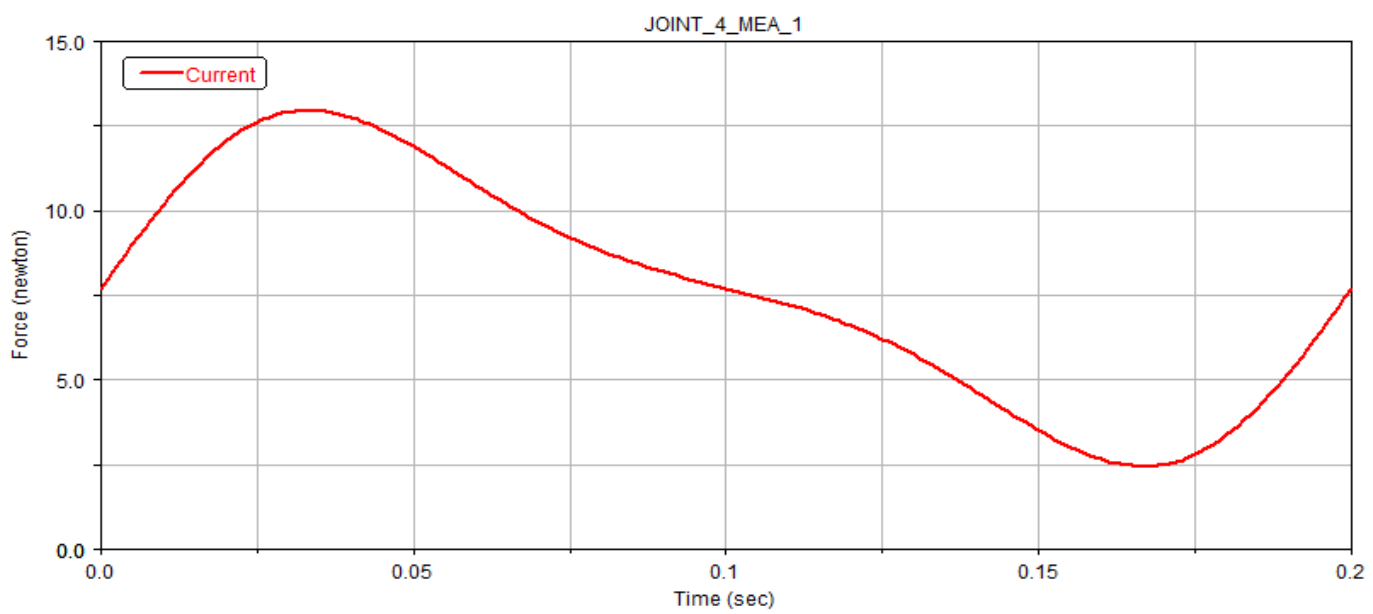

(b) diagonally ADAMS simulation results

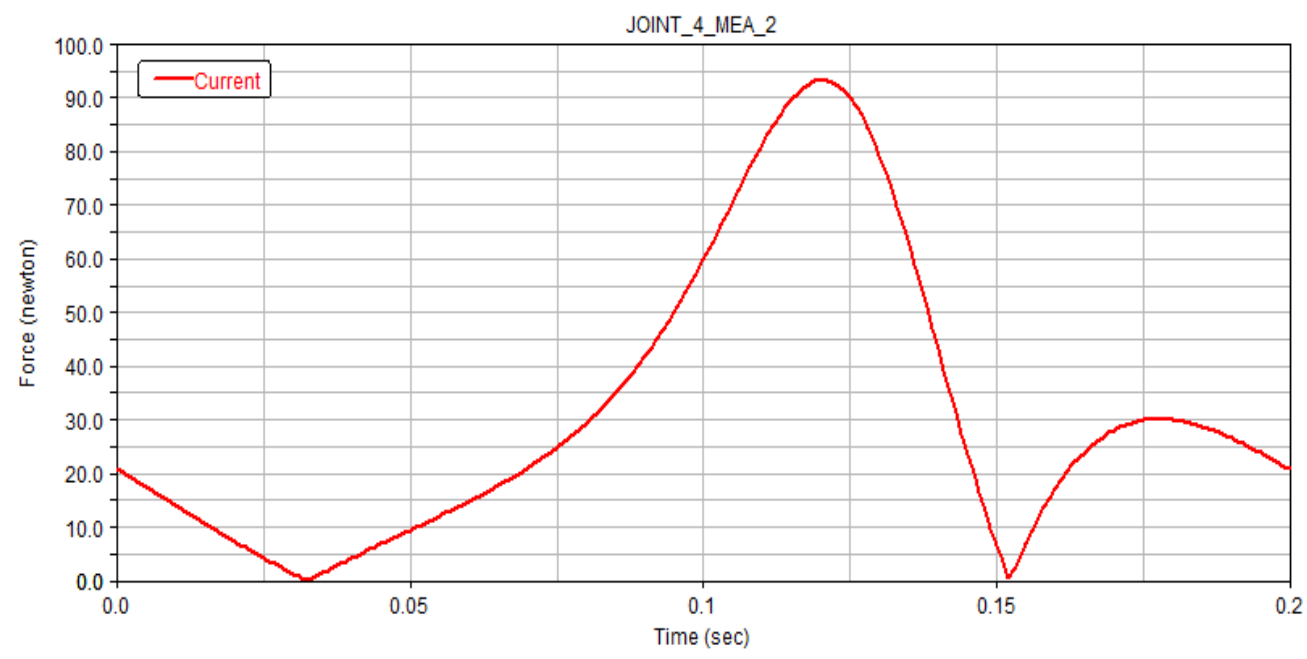

(c)Cut cut ADAMS simulation results

Fig -4: F-t graph of the three cutting modes 
And cutting of the miter angles are set at $45^{\circ}$, the simulation analysis can be obtained for each of the cutting mode v-t graph, Ft graph and a torque curve. Cutting mode of the three F-t graph performed Comparison, as shown in Fig.4.

Dividing the reciprocating speed shearing blade at work was 300 times / $\mathrm{min}$, i.e. 300 times per minute, the reciprocating cutting, the one round trip time is $0.2 \mathrm{~s}$. 3, a reciprocating cutting a simulation result, the simulation model for the toggle mechanism, not only the size of the cutting force and the link between the relevant forces, but also with changes in the angle between the connecting rod and cosine changes. Because different location each time motion simulation crank linkage and trends force was also different. The maximum cutting force can be obtained for each cutting patterns from the curve in Fig.3, as shown in Tab.1.

Table -1: The maximum of three cutting modes cutting force

\begin{tabular}{|l|l|l|l|}
\hline & Crosscutting & Beveling & Cutting \\
\hline $\operatorname{Max} \mathrm{F}(\mathrm{N})$ & 9.1975 & 12.9565 & 93.302 \\
\hline
\end{tabular}

From Tab.1, cross-cutting, beveling, cutting of three kinds of ways of cutting maximum cutting force values are in turn increases. The same work environment, dividing the shearing blade cutting forces, the smaller tool wear. So cutting back is a relatively good way of cutting.

\section{SIMULATION STUDY OF CUTTING ANGLE}

From the above simulation results, the cutting of a relatively good way of good cutting. But simulation angle cutting of the above simulation is $45^{\circ}$, but the actual dividing shear blade mounting angle can not reach $45^{\circ}$, in order to find out the cutting of a relatively reasonable cutting angle,following a different perspective on the use of ADAMS cutting of the simulation analysis.

The simulation model shown in Fig.3 (c) shows, sequentially changing the cutting angle $10^{\circ}, 20^{\circ}, 30^{\circ}, 40^{\circ}$, $50^{\circ}$. The simulation results obtained are shown in Tab. 2 below.

Table -2: The maximum parameters under different cutting angles

\begin{tabular}{|l|l|l|}
\hline Angle $\left({ }^{\circ}\right)$ & Max Torque $(\mathrm{N} \bullet \mathrm{mm})$ & $\operatorname{Max} \mathrm{F}(\mathrm{N})$ \\
\hline 10 & 604.9937 & 9.4772 \\
\hline 20 & 697.1816 & 14.7583 \\
\hline 30 & 920.3175 & 24.8019 \\
\hline 40 & 1466.9445 & 51.7924 \\
\hline 50 & 4592.7137 & 302.0784 \\
\hline
\end{tabular}

As can be seen from Tab.2, with the increase of the cutting angle, the value of the maximum value and the maximum torque of the cutting forces are gradually increasing, the cutting angle of $40^{\circ}$ and $50^{\circ}$, the change in torque and cutting force than large, especially when the cutting angle is $50^{\circ}$, the torque and cutting force become large.

\section{CONCLUSION}

The cutting force is to split the larger the shearing blades work advantageously, but the torque increases stability and reliability of the cutting device is disadvantageous. Therefore, the determination of the cutting angle of the cutting apparatus in the case to meet the actual requirements of the installation, try to select a large angle. And in the same work environment, dividing the shearing blade cutting forces, the smaller tool wear. So cutting back is a relatively good way of cutting.

\section{REFERENCES}

[1]. Zhang Yuxin,Wang Shuai.Design and Simulation of a new Garbage clean water boat actuator $[\mathrm{J}]$. Mechanical Design and Manufacturing .2011 April, the first four

[2]. Chinese Academy of Agricultural Mechanization Sciences compiled. Agricultural Machinery Design Manual [M] 2007

[3]. Fan Jinling. Harvester cutting device parametric modeling and finite element analysis [D]. Hebei Agricultural University, 2013

[4]. Zhu Congling, Liu Jianglong, Lu Wei. Combine reciprocating cutter actuator dynamics analysis [J]. Jiamusi University (Natural Science) .2004 March, Vol. 22 No. 1

[5]. Wang Guoqiang, Zhang Jinping, Ma cytorhodin virtual prototyping technology and its practice of the ADAMS [M] Xi'an: Northwestern University Press, 2002

[6]. Hou Shu of environmental protection and environmental dredging ship [J] ships, 1998 (6): 6 to 11

[7]. Li Zihua. "AGRICULTURAL MACHINERY." Beijing Agricultural Engineering University Press, Beijing 